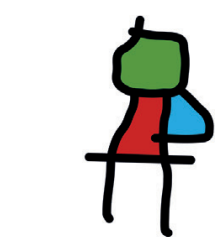

SEICAIP

\section{Allergologia et immunopathologia}

Sociedad Española de Inmunología Clínica, Alergología y Asma Pediátrica

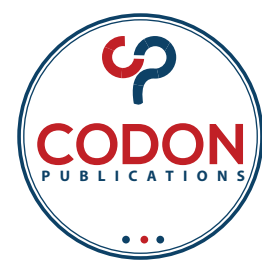

ORIGINAL ARTICLE

OPEN ACCESS (C) (1) (우

\title{
Curcumol inhibits PDGF-BB-induced proliferation and migration of airway smooth muscle cells by suppressing ERK/CREB pathway
}

\author{
Shihui Ling ${ }^{\mathrm{a}}$, Liya Zhanga, Yan Qian ${ }^{\mathrm{b}}$, Zhiguang Liu ${ }^{\mathrm{b}}$, Zhengdao Mao ${ }^{\mathrm{b}}$, Qian Zhang ${ }^{\mathrm{b} *}$
}

${ }^{a}$ Department of Emergency, The Affiliated Changzhou No.2, People's Hospital of Nanjing Medical University, Changzhou City, Jiangsu Province, China

${ }^{b}$ Department of Respiratory and Critical Care Medicine, The Affiliated Changzhou No.2, People's Hospital of Nanjing Medical University, Changzhou City, Jiangsu Province, China

Received 9 September 2021; Accepted 29 September 2021

Available online 1 January 2022

\section{KEYWORDS}

Curcumol;

asthma;

PDGF-BB, ERK/CREB

pathway;

airway smooth

muscle cells

\begin{abstract}
Background: Curcumol, possessing antiviral, antifungal, antimicrobial, anticancer, and antiinflammatory properties, has been widely used in treating cancers and liver fibrosis. The aim of this study was to determine the effect of curcumol on the progression of asthma.

Materials and methods: Curcumol was administrated to platelet-derived growth factor (PDGF)BB-stimulated airway smooth muscle cells (ASMCs). The proliferation of ASMCs was assessed by MTT and EdU incorporation assays. The apoptosis of ASMCs was measured by flow cytometry and Western blotting. The migration of ASMCs was evaluated by Transwell migration assay and Western blotting. The regulatory effects of curcumol on extracellular signal-regulated protein kinase (ERK)/CAMP response element-binding protein (CREB) pathway was evaluated by Western blotting.

Results: The proliferation and migration of ASMCs induced by PDGF-BB was suppressed, and the apoptosis of ASMCs was elevated by curcumol in a dose-dependent manner. The activation of ERK/CREB pathway induced by PDGF-BB was suppressed by curcumol.

Conclusion: Curcumol could suppress ERK/CREB pathway to inhibit proliferation and migration and promote apoptosis of PDGF-BB-stimulated ASMCs. These findings suggest that curcumol may act as a potential drug for asthma treatment.

(c) 2022 Codon Publications. Published by Codon Publications.
\end{abstract}

*Corresponding author: Qian Zhang, Department of Respiratory and Critical Care Medicine, The Affiliated Changzhou No.2, People's Hospital of Nanjing Medical University, No. 29 Xinglong Road, Changzhou City, Jiangsu Province, China. Email address: qian_zhang1635@ 163.com 


\section{Introduction}

Asthma is a common respiratory disorder affecting people of all age groups. ${ }^{1}$ It can be triggered by various factors such as respiratory infections, allergens, and airway irritants. ${ }^{1,2}$ The major symptoms of asthma are cough, chest tightness, wheezing, and shortness of breath, which arise from inflammation, hyperresponsiveness, and airway remodeling ${ }^{3,4}$ The airway smooth muscle cells (ASMCs) are involved in the inflammatory process, and secretory, proliferative, and contractile functioning of asthmatic airways, which play an important role in asthma pathophysiology. ${ }^{5}$ The increase of proliferation and migration of ASMCs can promote airway remodeling and cause irreversible obstruction, thereby aggravating asthma. ${ }^{7-9}$ The augment of ASMCs in asthma is induced by contractile agonists, proinflammatory cytokines as well as growth factors such as epidermal growth factor (EGF), platelet-derived growth factor (PDGF)-BB, and insulin-like growth factor-1 (IGF-1). ${ }^{10,11}$ PDGF and EGF have been reported to activate mitogen-activated protein kinase (MAPK)/extracellular signal-regulated protein kinase (ERK) and phosphatidylinositol 3-kinase (PI3K)/ protein kinase $B(A k t)$ signaling pathways to induce ASMCs proliferation. ${ }^{12,13}$ Thus, specific targeting of ASMCs for treating asthma has attracted a lot of attention. ${ }^{14}$

Current asthma treatments focus on reducing the symptoms through ameliorating inflammation, and the drugs used primarily contain beta-adrenoceptor-2 ( $\beta 2)$ agonists, leukotriene antagonists, and corticosteroids. ${ }^{15}$ However, these drugs produce various side effects such as osteoporosis, cardiovascular effects, headaches, and vomiting. ${ }^{16}$ Traditional herbal medicines have been widely applied for the treatment, cure, and prevention of many diseases. ${ }^{17}$ Accumulating literature suggests that traditional herbal medicines may be recognized as a potential alternative for treating asthma, because the extracts of some medical plants (e.g., Herissantia tiubae, Aster yomena) can effectively attenuate asthma symptoms and have comparable efficacies with the commonly used asthma drugs in the modern system of medicine. ${ }^{18,19}$ Nevertheless, there is still a lack of information on the study of the toxicological profiles and clinical tests of plant extracts. ${ }^{16}$ Curcumol, as a bioactive sesquiterpenoid, is extracted from Rhizoma Curcumae.(6) ${ }^{20}$ It has various pharmacological properties (e.g., antiviral, antifungal, antimicrobial, anticancer, and anti-inflammatory) with low cytotoxicity. ${ }^{17}$ For instance, curcumol can inhibit cellular proliferation in different cancers, including hepatocarcinoma, colorectal cancer, and lung carcinoma. ${ }^{21-23}$ Curcumol suppresses the migration and adhesion of hepatic stellate cells to decrease liver fibrosis(7). ${ }^{24}$ Moreover, curcumol has been proved to ameliorate airway remodeling and lung inflammation in a mouse model of chronic asthma(8). ${ }^{25}$ However, the molecular mechanisms of curcumol in asthma are rarely reported.

It is accepted that curcumol affects different diseases by regulating many signaling pathways such as Nuclear factor kappa B (NF-kB), PI3K/AKT, and MAPK/ERK pathways(9). ${ }^{26}$ Lee et al. have demonstrated that ERK activation promotes the proliferation of $\operatorname{ASMCs}(10) .{ }^{27}$ Deng et al. have indicated that inhibiting the activation of ERK and AKT caused by FSTL1 knockdown suppresses the proliferation and migration of ASMCs(11). ${ }^{28}$ Besides, a key downstream target of ERK, CAMP Response Element-Binding (CREB) protein, is associated with inflammation, deposition of extracellular matrix (ECM), and proliferation of different cells. ${ }^{29,30}$ However, whether curcumol regulates ERK/ CREB pathway to affect the growth of ASMCs has not been reported.

Hence, in the present study, we have evaluated the effect of curcumol on the proliferation, apoptosis, and migration of ASMCs. In addition, we explored the interactive relationship between curcumol and ERK/CREB pathway in ASMCs.

\section{Materials and methods}

\section{Cell culture}

Human ASMCs isolated from primary and lobar bronchi were purchased from Bena Culture Collection (Beijing, China). ASMCs were cultured in Dulbecco's Modified Eagle's medium (DMEM; Gibco, Grand Island, NY, USA) supplemented with $10 \%$ fetal bovine serum (FBS), $100 \mathrm{U} / \mathrm{mL}$ penicillin, and $100 \mu \mathrm{g} / \mathrm{mL}$ streptomycin at $37^{\circ} \mathrm{C}$ in a humidified incubator containing $5 \% \mathrm{CO}_{2}$.

\section{Groups}

Curcumol (MedChemExpress [MCE], Monmouth Junction, NJ, USA) was dissolved in absolute ethyl alcohol to a concentration of $10 \mathrm{mg} / \mathrm{mL}$ and diluted with serum-free DMEM to the required concentration before use. PDGF-BB (SigmaAldrich, St. Louis, MO, USA) was dissolved in DMEM with $0.1 \%$ bovine serum albumin (BSA). ASMCs were incubated for $24 \mathrm{~h}$ with DMEM containing 10\% FBS and starved in serum-free DMEM for $24 \mathrm{~h}$ to synchronize cell cycle. After cell synchronization, cells were divided into the following five groups: control, PDGF-BB, PDGF-BB + curcumol $10 \mu \mathrm{mol} / \mathrm{L}$, PDGF-BB + curcumol $20 \mu \mathrm{mol} / \mathrm{L}$, and PDGF-BB + curcumol $40 \mu \mathrm{mol} / \mathrm{L}$. Control group: both PDGF-BB and curcumol were not added into the cells, and cells were incubated only with serum-free DMEM. PDGF-BB group: serum-free DMEM containing $0.1 \%$ ethyl alcohol was added into cells for $1 \mathrm{~h}$ for pre-incubation and PDGF-BB (20 ng/ $\mathrm{mL}$ ) was added and incubated for another $48 \mathrm{~h}$. PDGF-BB + curcumol $10 \mu \mathrm{mol} / \mathrm{L}$ group: cells were pre-incubated with curcumol $(10 \mu \mathrm{mol} / \mathrm{L})$ for $1 \mathrm{~h}$ to promote drug absorption; PDGF-BB $(20 \mathrm{ng} / \mathrm{mL})$ was then added into the cells for $48 \mathrm{~h}$ to stimulate re-entry into the cell cycle and induce proliferation. PDGF-BB + curcumol $20 \mu \mathrm{mol} / L$ group: the same treatment as performed in PDGF-BB + curcumol 10 $\mu \mathrm{mol} / \mathrm{L}$ group, except the dose of curcumol was $20 \mu \mathrm{mol} / \mathrm{L}$. PDGF-BB + curcumol $40 \mu \mathrm{mol} / L$ group: The same treatment as performed in PDGF-BB + curcumol $10 \mu \mathrm{mol} / \mathrm{L}$ group, except that the dose of curcumol was $40 \mu \mathrm{mol} / \mathrm{L}$.

\section{Cell viability assay}

The effect of curcumol on the viability of ASMCs or PDGFBB-induced ASMCs was measured by MTT assay. ASMCs were cultured with DMEM containing 10\% FBS in 96-well 
plates $\left(200 \mu \mathrm{L}\right.$ per well, $2.5 \times 10^{4}$ cells $\left./ \mathrm{mL}\right)$ for $24 \mathrm{~h}$. These were starved in serum-free DMEM for $24 \mathrm{~h}$ to synchronize cell cycle. Next, for the effect of curcumol on ASMC viability, the cells were treated with curcumol $(0,10,20,40$, $60,80$, or $100 \mu \mathrm{mol} / \mathrm{L})$ for $48 \mathrm{~h}$. For the effect of curcumol on the viability of PDGF-BB-induced ASMC, the cell groups were designed and treated as described above.

After $48 \mathrm{~h}$ of incubation, MTT $(20 \mu \mathrm{L}, 5 \mathrm{mg} / \mathrm{mL}$; SigmaAldrich) was added to each well in 96-well plates and incubated for $4 \mathrm{~h}$ to form formazan crystals. After discarding the medium, dimethyl sulfoxide (DMSO; Sigma-Aldrich) was added to solubilize the crystals. The absorbance of the samples was evaluated by a microplate (Tecan's Infinite 200 PRO, Myron, Switzerland) at $570 \mathrm{~nm}$ (detection wavelength) and $630 \mathrm{~nm}$ (reference wavelength; background). The data were calculated as follows:

$$
\begin{aligned}
\text { Cell viability }(\%)= & (\text { Experimental group OD value } \\
- & \text { Blank group OD value }) / \\
& (\text { Control group OD value }- \text { Blank group } \\
& \text { OD value }) \times 100 .
\end{aligned}
$$

\section{EdU incorporation assay}

For EdU incorporation assay, ASMCs were incubated with DMEM containing 10\% fetal bovine serum (FBS) for $24 \mathrm{~h}$ in 24-well plates (Density: $1 \times 10^{4}$ cells per well) and synchronized by $24-\mathrm{h}$ serum starvation. ASMCs were treated with curcumol $(0,10,20$, or $40 \mu \mathrm{mol} / \mathrm{L})$ for $1 \mathrm{~h}$ and stimulated with or without PDGF-BB (20 ng/mL) for $48 \mathrm{~h}$. Next, EdU Staining Proliferation Kit (ABCAM), Abcam, Cambridge, UK, was used following manufacturer's protocol, and ASMCs were visualized by Leica DM2500 fluorescence microscope (Wetzlar, Germany).

\section{Cell apoptosis assay}

ASMCs were digested with trypsin for $3 \mathrm{~min}$, added with complete medium, and centrifuged for $5 \mathrm{~min}$ at $1000 \mathrm{rpm}$. After removing the supernatant and washing twice with PBS, ASMCs were added with $1 \times$ binding buffer. Each group was divided into four equal subgroups, including unstained control, only Annexin- $\mathrm{V}$ stain, only $\mathrm{PI}$ stain, and Annexin-V $+\mathrm{PI}$ stain subgroups. The cell suspension $\left(1 \times 10^{6} \mathrm{cells} / \mathrm{mL}\right.$, $100 \mu \mathrm{L})$ was added into a test tube with Annexin-V $(5 \mu \mathrm{L})$ and/or PI $(5 \mu \mathrm{L})$, gently mixed and incubated in the dark for $30 \mathrm{~min}$, followed by adding $400 \mu \mathrm{L}$ of $1 \times$ binding buffer. The apoptosis was detected by flow cytometry (BD Bioscience, San Diego, CA, USA) and the apoptotic ratio was analyzed as described in literature (12). ${ }^{31}$

\section{Cell migration assay}

The migration of ASMCs was measured by Transwell migration assay (Corning Incorporated, Corning, NY, USA). After cell synchronization, ASMCs were harvested, resuspended in serum-free DMEM, and added in the upper chamber. The same medium was added to the lower chamber as well. After allowing to adhere for $1 \mathrm{~h}$, cells were pretreated with curcumol for $1 \mathrm{~h}$ in the upper chamber, and
PDGF-BB was added to the lower chamber. ASMCs were allowed to migrate for $24 \mathrm{~h}$ at $37^{\circ} \mathrm{C}$. Next, the cells remaining on the upper surface of the chamber were wiped off with cotton swab, and the migrated cells were fixed with $4 \%$ formaldehyde and stained with $5 \%$ crystal violet. The cells were imaged and counted using a microscope (Nikon Corporation, Tokyo, Japan). The cell number was counted by the ImageJ software.

\section{Western blot test}

ASMCs were lysed by RIPA lysis buffer, centrifuged at $4^{\circ} \mathrm{C}$ for $15 \mathrm{~min}$ at $12,000 \mathrm{rpm}$ and the supernatant was procured. The concentration of proteins was assessed by the BCA method. Proteins ( $20 \mu \mathrm{g}$ per hole) were added in the loading holes of $10 \%$ SDS-PAGE, followed by transferring to PVDF membranes. After being blocked with $5 \%$ non-fat milk for $2 \mathrm{~h}$, the membranes were rinsed with Tris-buffered saline plus Tween 20 (TBST) for five times and incubated with primary antibodies at $4^{\circ} \mathrm{C}$ overnight. Primary antibodies, purchased from Cell Signaling Technology (Boston, MA, USA) (dilution 1/1000), included Bax (\#14796), Bcl-2 (\#3498), cleaved Caspase-3 (\#9654), MMP9 (\#13667), $\alpha$ SMA (\#19245), p-ERK1/2 (\#8544), ERK1/2 (\#9102), p-CREB (\#9198), CREB (\#9197), and $\beta$-actin (\#4970). Subsequently, the membranes were incubated with secondary antibodies (anti-rabbit IgG, HRP-linked antibody, \#7074, dilution 1/2000; Cell Signaling Technology) at $37^{\circ} \mathrm{C}$ for $1 \mathrm{~h}$ and washed with TBST for four times. Proteins in the membranes were visualized by an enhanced chemiluminescence reagents (Sangon Biotech, Shanghai, China). The quantification of the proteins was analyzed by the ImageJ software as described in literature. ${ }^{32}$

\section{Statistical analysis}

Each experiment was independently repeated for three times. Data were expressed as mean \pm standard error (SE) and analyzed by the GraphPad Prism 7.0 software. Statistically significant difference was evaluated by Student's $t$-test for comparisons between two groups and ANOVA with Bonferroni multiple comparisons test for comparisons between more than two groups. Statistical significance was designated as $\mathrm{P}<0.05$.

\section{Results}

\section{Curcumol inhibits the proliferation of ASMCs induced by PDGF-BB}

The effect of curcumol on the proliferation of ASMCs was assessed by MTT and EdU incorporation assays. MTT assay indicated that curcumol at the concentration of 10, 20, 40 $\mu \mathrm{mol} / \mathrm{L}$ had no significant effect on the viability of ASMCs, but the higher concentration of curcumol $(60,80,100$ $\mu \mathrm{mol} / \mathrm{L})$ demonstrated an obvious cytotoxicity to ASMCs, evidenced by decreased cell viability (Figure 1A). PDGF-BB stimulation significantly enhanced the viability of ASMCs compared with the control group (Figure 1B). Nevertheless, 
(A)

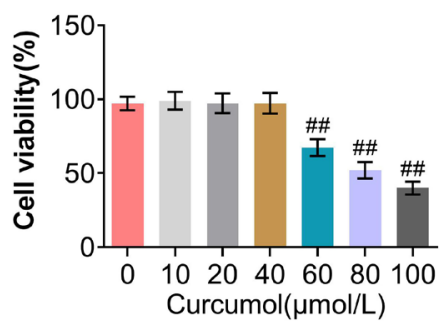

(C)

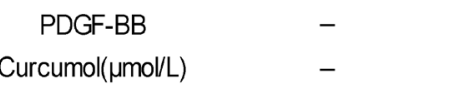

EdU
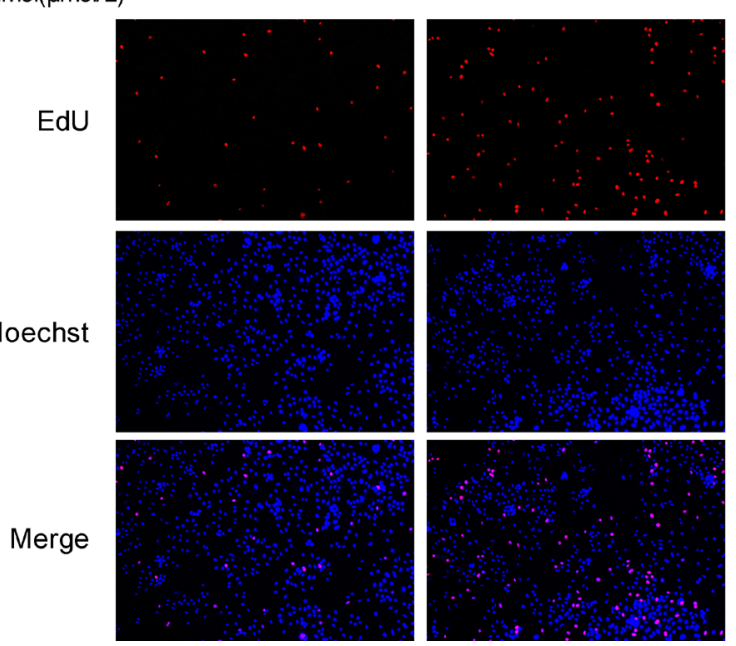

(B)

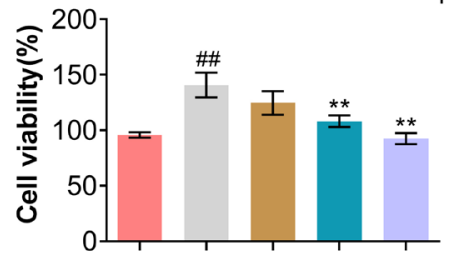

PDGF-BB+Curcumol 10umol/L

PDGF-BB+Curcumol $20 \mu \mathrm{mol} / \mathrm{L}$ PDGF-BB+Curcumol $40 \mu \mathrm{mol} / \mathrm{L}$
(D)
Control
PDGF-BB
PDGF-BB+Curcumol $10 \mu \mathrm{mol} / \mathrm{L}$
PDGF-BB+Curcumol $20 \mu \mathrm{mol} / \mathrm{L}$
PDGF-BB+Curcumol 40 $\mu \mathrm{mol} / \mathrm{L}$

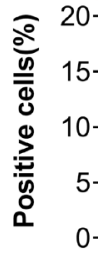

$10-$

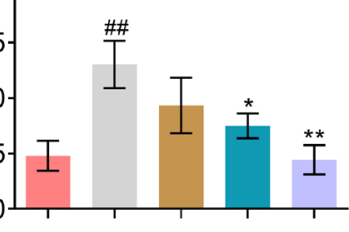

20
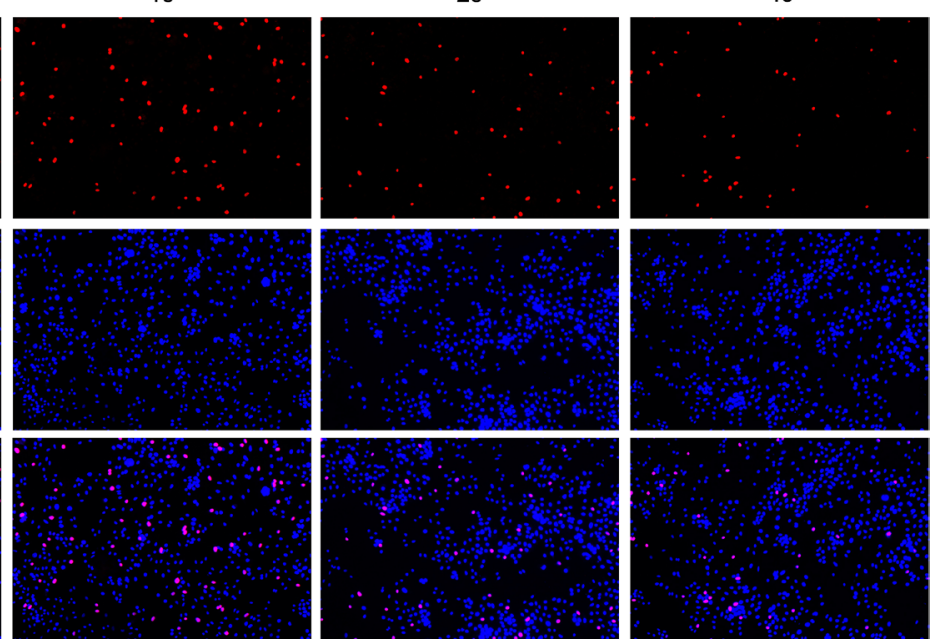

Figure 1 Curcumol inhibits the proliferation of ASMCs induced by PDGF-BB. (A) The effects of curcumol at various doses on the viability of ASMCs were measured by MTT assay. (B) The effects of curcumol on the viability of ASMCs induced by PDGF-BB were assessed by MTT assay. (C) and (D) The proliferation of ASMCs was measured by EdU incorporation assay. ${ }^{\# P}<0.01$ (PDGF-BB versus control); ${ }^{*} \mathrm{P}<0.05,{ }^{* *} \mathrm{P}<0.01$ (PDGF-BB + curcumol [10, 20, or $\left.40 \mu \mathrm{mol} / \mathrm{L}\right]$ versus PDGF-BB).

the increased viability of ASMCs induced by PDGF-BB was suppressed by curcumol treatment in a dose-dependent manner (Figure 1B). In addition, EdU incorporation assay depicted that, compared with the control group, the EdUpositive cell number was obviously increased by PDGF-BB treatment, while the PDGF-BB-induced enhanced number of EdU-positive cells was decreased by curcumol treatment in a dose-dependent manner (Figures $1 \mathrm{C}$ and 1D). Collectively, curcumol inhibited the proliferation of ASMCs induced by PDGF-BB.

\section{Curcumol promotes the apoptosis of ASMCs induced by PDGF-BB}

The effect of curcumol on the apoptosis of ASMCs was examined by flow cytometry and Western blotting. As presented in Figures $2 \mathrm{~A}$ and $2 \mathrm{~B}$, the apoptosis of ASMCs was decreased by PDGF-BB, which was elevated by curcumol treatment in a dose-dependent manner. In addition, reduction of pro-apoptotic proteins (Bax and cleaved Caspase-3) and induction of anti-apoptosis protein $\mathrm{Bcl}-2$ caused by PDGF-BB were reversed by curcumol treatment in a dose-dependent manner (Figure 2C). Therefore, curcumol promoted the apoptosis of PDGF-BB-stimulated ASMCs.

\section{Curcumol suppresses the migration of ASMCs induced by PDGF-BB}

The effect of curcumol on the migration of ASMCs was detected by transwell migration assay and Western blot test. In comparison with the control, PDGF-BB greatly elevated the migration number of ASMCs (Figures $3 \mathrm{~A}$ and $3 B)$. Compared with the treatment of PDGF-BB alone, curcumol suppressed the migration number of ASMCs in a dose-dependent manner (Figures 3A and 3B). Western blot test indicated that PDGF-BB obviously increased the protein expressions of MMP 9 and $\alpha$-SMA as compared with the control group (Figures $3 C$ and 3D). However, these enhancements were reversed by curcumol in a dose-dependent manner (Figures 3C and 3D). Therefore, curcumol suppressed the migration of ASMCs induced by PDGF-BB.

\section{Curcumol suppresses the activation of ERK/CREB pathway induced by PDGF-BB}

Western blotting was used to explore whether the molecular mechanism of curcumol in the progression of asthma was related to ERK/CREB pathway. Compared with the 
(A)
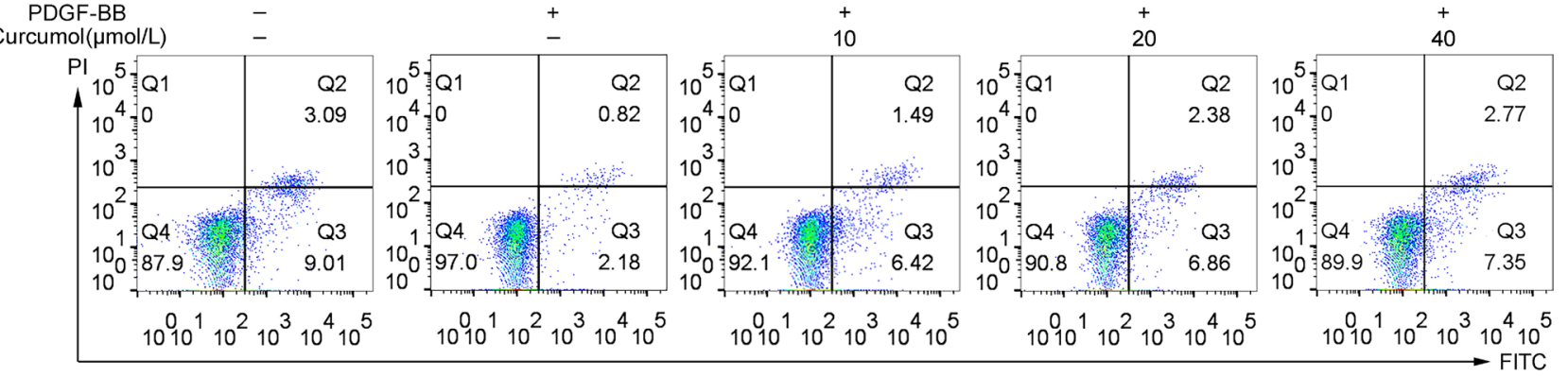

(B)

(C)
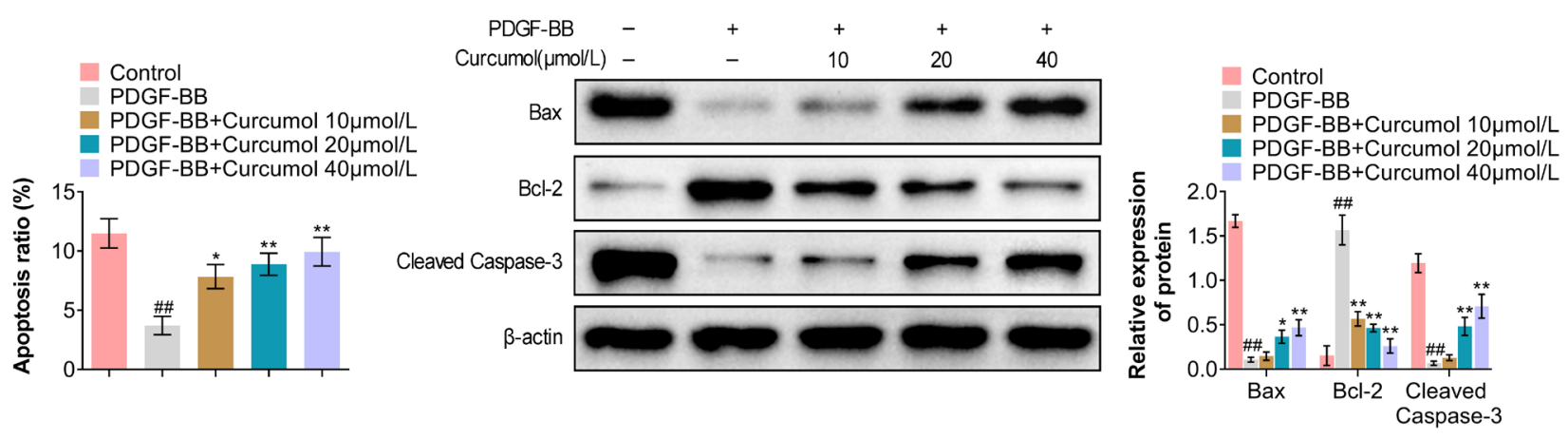

Figure 2 Curcumol promotes the apoptosis of ASMCs induced by PDGF-BB. (A) and (B) The apoptosis of ASMCs was detected by flow cytometry. (C) The protein expressions of $\mathrm{Bax}, \mathrm{Bcl}-2$, and cleaved Caspase- 3 were determined by Western blotting. ${ }^{\# \# P}<0.01$ (PDGF-BB versus control); ${ }^{*} \mathrm{P}<0.05,{ }^{* *} \mathrm{P}<0.01$ (PDGF-BB + curcumol [10, 20, or $\left.40 \mu \mathrm{mol} / \mathrm{L}\right]$ versus PDGF-BB).

(A) $\begin{gathered}\text { PDGF-BB } \\ \text { Curcumol( }(\mu \mathrm{mol} / \mathrm{L})\end{gathered}$
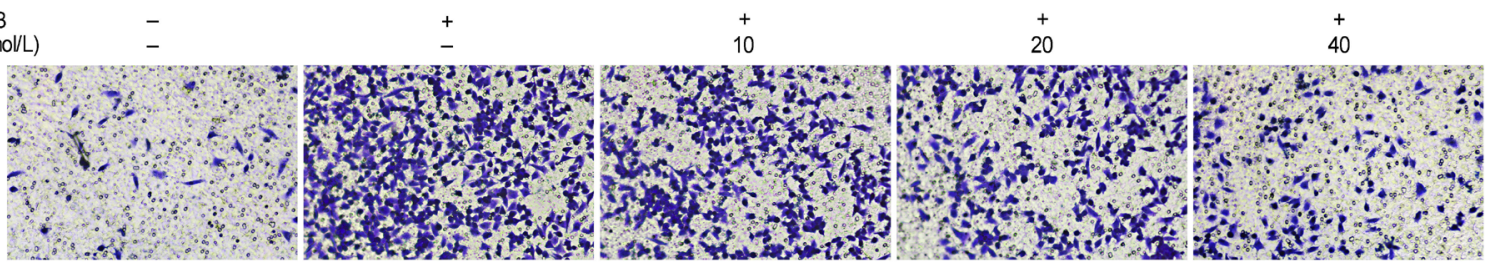

(B)

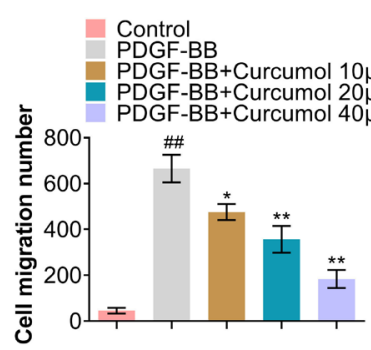

(C)

$\begin{array}{cccccc}\text { PDGF-BB } & - & + & + & + & + \\ \text { Curcumol( }(\mu \mathrm{mol} / \mathrm{L}) & - & - & 10 & 20 & 40\end{array}$

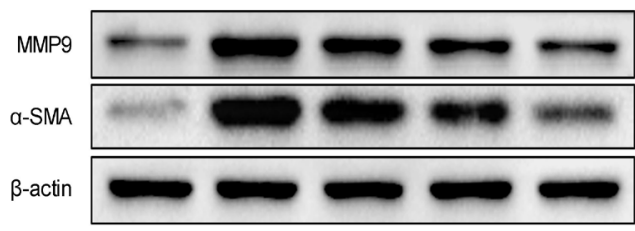

(D)

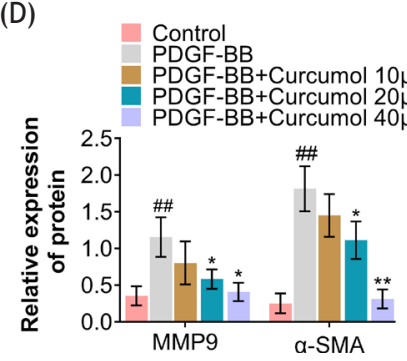

Figure 3 Curcumol suppresses the migration of ASMCs induced by PDGF-BB. (A) and (B) The migration of ASMCs was determined by transwell migration. (C) and (D) The protein expressions of MMP9 and $\alpha$-SMA were examined by Western blotting. ${ }^{\# \# P}<0.01$ (PDGF-BB versus control); ${ }^{*} \mathrm{P}<0.05$, ${ }^{* *} \mathrm{P}<0.01$ (PDGF-BB + curcumol [10, 20, or $\left.40 \mu \mathrm{mol} / \mathrm{L}\right]$ versus PDGF-BB).

control, PDGF-BB significantly increased the expressions of $\mathrm{p}-\mathrm{ERK} 1 / 2$ and $\mathrm{p}$-CREB, indicating that PDGF-BB activated ERK/CREB pathway (Figure 4). Nevertheless, curcumol treatment decreased the expressions of $\mathrm{p}$-ERK1/2 and $\mathrm{p}$-CREB in a dose-dependent manner (Figure 4). Hence, curcumol suppressed the activation of ERK/CREB pathway induced by PDGF-BB.

\section{Discussion}

Since the aberrant increase in proliferation and migration of ASMC is intensely associated with the formation of airway remodeling, ${ }^{7}$ asthma treatment that targets ASMCs helps to attenuate structural changes in the airway wall(13).${ }^{14}$ PDGF-BB is critical for promoting the proliferation 

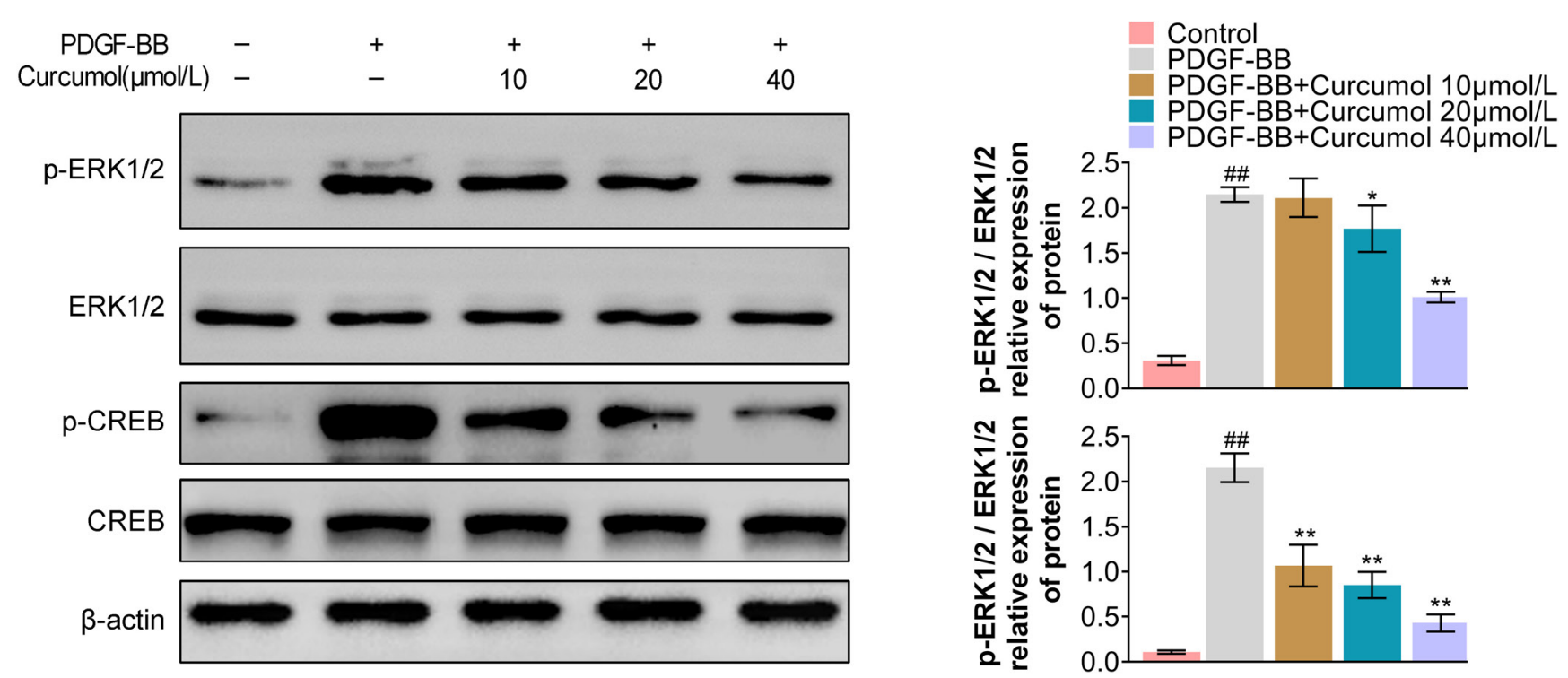

Figure 4 Curcumol suppresses the activation of ERK/CREB pathway induced by PDGF-BB. The protein expressions of $\mathrm{p}$-ERK1/2, ERK1/2, P-CREB, and CREB were measured by Western blotting. ${ }^{\# \# P}<0.01$ (PDGF-BB versus control); ${ }^{*} \mathrm{P}<0.05,{ }^{* *} \mathrm{P}<0.01$ (PDGF-BB + curcumol [10, 20, or $40 \mu \mathrm{mol} / \mathrm{L}]$ versus PDGF-BB).

and migration of $\mathrm{ASMCs} ;{ }^{33}$ hence, the present study used PDGF-BB to stimulate ASMCs. The experimental results indicated that PDGF-BB significantly promoted the proliferation and migration of ASMC and yet suppressed apoptosis.

Curcumol has been reported to possess antiviral, antifungal, antimicrobial, anticancer, and anti-inflammatory properties, hence it has been widely used in many diseases such as cancers and liver fibrosis. ${ }^{17,21-24}$ Importantly, Jia et al. have demonstrated that curcumol helps in treating airway remodeling and lung inflammation in chronic asthmatic mice. ${ }^{25}$ However, the in vitro experimental effect of curcumol on asthma has not been studied. Therefore, this study detected the effect of curcumol on PDGF-BB-stimulated ASMCs. The results indicated that the increased cell viability and EdU-positive cell number induced by PDGF-BB was downregulated by curcumol in a dose-dependent manner. In comparison to treatment with PDGF-BB alone, introduction of curcumol obviously induced the apoptosis of ASMCs in a dose-dependent manner. In addition, the increased migratory cell numbers and high expressions of MMP 9 and $\alpha$-SMA induced by PDGF-BB were inhibited by curcumol in a dose-dependent manner. Therefore, curcumol suppressed PDGF-BB-induced proliferation and migration of ASMCs but promoted apoptosis. Curcumol could act as a potential factor for asthma treatment.

In order to further explore the molecular mechanism of curcumol in the progression of asthma, the regulatory role of curcumol on ERK/CREB pathway was determined. The ERK/CREB pathway plays an important role in various cellular processes such as proliferation, migration, and inflammation. ${ }^{27-29}$ For example, the activation of ERK/CREB signaling suppresses apoptosis and inflammation in the renal tubular cells under hypoxia-reoxygenation injury. ${ }^{34}$ Its activation can sustain mitochondrial homeostasis, rescue mitophagy activity, and inhibit hepatocyte apoptosis. ${ }^{35}$ Activated ERK/CREB signaling is also beneficial for the migration and proliferation of vascular smooth muscle cells. ${ }^{36}$ Nevertheless, deactivation of ERK/CREB signaling inhibits proliferation and migration of ASMC. ${ }^{28}$ This work demonstrated that the activation of ERK/CREB pathway was induced by PDGF-BB in ASMCs; however, its activation was suppressed by curcumol. Taken together, it is speculated that curcumol could suppress ERK/CREB pathway to inhibit proliferation and migration and promote apoptosis in PDGF-BB-stimulated ASMCs.

\section{Conclusion}

Results of the present study indicated that curcumol had inhibitory effect on the proliferation and migration of PDGF-BB-induced ASMCs by suppressing the activity of ERK/ CREB pathway. These findings contribute to understanding the molecular mechanism of curcumol in the progression of asthma and suggest that curcumol could act as a potential drug for treating asthma. Nevertheless, the present study used ASMCs from a subset of asthmatic patients, and therefore the findings of this study have its limitations. Hence, these observations require to be further validated by extensive biological experiments and clinical trials.

\section{Funding}

This study was supported by the following grants to Qian Zhang: Jiangsu Province Social Development Project (BE2020651), in part Jiangsu Province "333 Talents" Project (BRA2020015), and the Changzhou Sci \& Tech Program (CE20205023).

\section{Competing interests}

The authors state that there are no conflicts of interest to disclose. 


\section{Author Contributions}

Shihui Ling and Liya Zhang designed the study, supervised data collection; Yan Qian and Zhiguang Liu analyzed and interpreted the data; Zhengdao Mao and Qian Zhang prepared the manuscript for publication and reviewed its draft. All authors read and approved the final manuscript.

\section{References}

1. Wark PAB, Ramsahai JM, Pathinayake P, Malik B, Bartlett NW. Respiratory viruses and asthma. Sem Resp Crit Care Med. 2018;39(1):45-55. https://doi.org/10.1055/s-0037-1617412

2. Wu TD, Brigham EP, McCormack MC. Asthma in the primary care setting. Med Clin North Am. 2019;103(3):435-52. https:// doi.org/10.1016/j.mcna.2018.12.004

3. Tanaka K, Arakawa M, Miyake Y. Perinatal smoking exposure and risk of asthma in the first three years of life: A prospective prebirth cohort study. Allergologia et Immunopathologia. 2020;48(6):530-6. https://doi.org/10.1016/j.aller.2020.03.008

4. Boulet LP, Boulay M. Asthma-related comorbidities. Exp Rev Resp Med. 2011;5(3):377-93. https://doi.org/10.1586/ers.11.34

5. Liu G, Cooley MA, Nair PM, Donovan C, Hsu AC, Jarnicki AG, et al. Airway remodelling and inflammation in asthma are dependent on the extracellular matrix protein fibulin-1c. J Pathol. 2017;243(4):510-23. https://doi.org/10.1002/path.4979

6. Yeganeh B, Xia C, Movassagh H, Koziol-White C, Chang Y, Al-Alwan L, et al. Emerging mediators of airway smooth muscle dysfunction in asthma. Pulm Pharmacol Ther. 2013;26(1):105-11. https://doi.org/10.1016/j.pupt.2012.06.011

7. Redhu NS, Shan L, Movassagh H, Gounni AS. Thymic stromal lymphopoietin induces migration in human airway smooth muscle cells. Sci Rep. 2013;3:2301. https://doi.org/10.1038/srep02301

8. Salter B, Pray C, Radford K, Martin JG, Nair P. Regulation of human airway smooth muscle cell migration and relevance to asthma. Respir Res. 2017;18(1):156. https://doi.org/10.1186/ s12931-017-0640-8

9. Zhao L, Shi X, Wang N, Liu C, Wang J. YAP1, targeted by miR375 , enhanced the pro-angiogenesis of airway smooth muscle cells in asthma via STAT3 activation. Cell Cycle (Georgetown, TX). 2020;19(11):1275-84. https://doi.org/10.1080/15384101.20 20.1746874

10. Liu W, Kong H, Zeng X, Wang J, Wang Z, Yan X, et al. Iptakalim inhibits PDGF-BB-induced human airway smooth muscle cells proliferation and migration. Exp Cell Res. 2015;336(2):204-10. https://doi.org/10.1016/j.yexcr.2015.06.020

11. Stamatiou R, Paraskeva E, Gourgoulianis K, Molyvdas PA, Hatziefthimiou A. Cytokines and growth factors promote airway smooth muscle cell proliferation. ISRN Inflamm. 2012;2012:731472. https://doi.org/10.5402/2012/731472

12. Karpova AY, Abe MK, Li J, Liu PT, Rhee JM, Kuo WL, et al. MEK1 is required for PDGF-induced ERK activation and DNA synthesis in tracheal myocytes. Am J Physiol. 1997;272(3, Pt 1):L558-65. https://doi.org/10.1152/ajplung.1997.272.3.L558

13. Krymskaya VP, Penn RB, Orsini MJ, Scott PH, Plevin RJ, Walker TR, et al. Phosphatidylinositol 3-kinase mediates mitogen-induced human airway smooth muscle cell proliferation. Am J Physiol. 1999;277(1):L65-78. https://doi.org/10.1152/ajplung. 1999.277.1.L65

14. Zuyderduyn S, Sukkar MB, Fust A, Dhaliwal S, Burgess JK. Treating asthma means treating airway smooth muscle cells. Eur Respir J. 2008;32(2):265-74. https://doi.org/10.1183/09031936. 00051407

15. Kwah JH, Peters AT. Asthma in adults: Principles of treatment. Allergy Asthma Proc. 2019;40(6):396-402. https://doi. org/10.2500/aap.2019.40.4256
16. Azman S, Sekar M, Bonam SR, Gan SH, Wahidin S, Lum PT, et al. Traditional medicinal plants conferring protection against ovalbumin-induced asthma in experimental animals: A review. J Asthma Allergy. 2021;14:641-62. https://doi.org/10.2147/ JAA.S296391

17. Wei W, Rasul A, Sadiqa A, Sarfraz I, Hussain G, Nageen B, et al. Curcumol: From plant roots to cancer roots. Int J Biol Sci. 2019;15(8):1600-9. https://doi.org/10.7150/ijbs.34716

18. Mozzini Monteiro T, Ferrera Costa H, Carvalho Vieira G, Rodrigues Salgado PR, da Silva Stiebbe Salvadori MG, de Almeida RN, et al. Anti-asthmatic and anxiolytic effects of Herissantia tiubae, a Brazilian medicinal plant. Immun Inflamm Dis. 2016;4(2):201-12. https://doi.org/10.1002/ iid3.107

19. Sim JH, Lee HS, Lee S, Park DE, Oh K, Hwang KA, et al. Antiasthmatic activities of an ethanol extract of Aster yomena in an ovalbumin-induced murine asthma model. J Med Food. 2014;17(5):606-11. https://doi.org/10.1089/jmf.2013.2939

20. Yan D, Deng S, Gan W, Li S, Li Y. Curcumol attenuates epithelial-mesenchymal transition of nasopharyngeal carcinoma cells via TGF-B1. Mol Med Rep. 2018;17(6):7513-20. https://doi. org/10.3892/mmr.2018.8817

21. Huang LZ, Wang J, Lu FT, Yang FC, Chen X, Hong X, et al. Mechanism study on anti-proliferative effects of curcumol in human hepatocarcinoma HepG2 cells. Zhongguo Zhong yao za zhi = Zhongguo zhongyao zazhi. China J Chin Mater Med. 2013;38(11):1812-5.

22. Liu H, Wang J, Tao Y, Li X, Qin J, Bai Z, et al. Curcumol inhibits colorectal cancer proliferation by targeting miR-21 and modulated PTEN/PI3K/Akt pathways. Life Sci. 2019;221:35461. https://doi.org/10.1016/j.lfs.2019.02.049

23. Tang QL, Guo JQ, Wang QY, Lin HS, Yang ZP, Peng T, et al. Curcumol induces apoptosis in SPC-A-1 human lung adenocarcinoma cells and displays anti-neoplastic effects in tumor bearing mice. Asian Pacific J Cancer Prev (APJCP). 2015;16(6):2307-12. https://doi.org/10.7314/APJCP.2015.16.6.2307

24. Jia Y, Gao L, Yang X, Zhang F, Chen A, Wang S, et al. Blockade of periostin-dependent migration and adhesion by curcumol via inhibition of nuclear factor kappa B signaling in hepatic stellate cells. Toxicology. 2020;440:152475. https://doi. org/10.1016/j.tox.2020.152475

25. Jia S, Guo P, Lu J, Huang X, Deng L, Jin Y, et al. Curcumol ameliorates lung inflammation and airway remodeling via inhibiting the abnormal activation of the Wnt/B-catenin pathway in chronic asthmatic mice. Drug Design Dev Ther. 2021;15:2641-51. https://doi.org/10.2147/DDDT.S292642

26. Hashem S, Nisar S, Sageena G, Macha MA, Yadav SK, Krishnankutty $R$, et al. Therapeutic effects of curcumol in several diseases; an overview. Nutr Cancer. 2021;73(2):181-95. https://doi.org/10.1080/01635581.2020.1749676

27. Lee JH, Johnson PR, Roth M, Hunt NH, Black JL. ERK activation and mitogenesis in human airway smooth muscle cells. Am J Physiol Lung Cell Mol Physiol. 2001;280(5):L1019-29. https://doi.org/10.1152/ajplung.2001.280.5.L1019

28. Deng $Y$, Zhang $Y$, Wu $H$, Shi Z, Sun X. Knockdown of FSTL1 inhibits PDGF-BB-induced human airway smooth muscle cell proliferation and migration. Mol Med Rep. 2017;15(6):3859-64. https://doi.org/10.3892/mmr.2017.6439

29. Li G, Jiang Q, Xu K. CREB family: A significant role in liver fibrosis. Biochimie. 2019;163:94-100. https://doi.org/10.1016/j. biochi.2019.05.014

30. Zirnask H, Pöllanen $P$, Suutre $S$, Kuuslahti $M$, Kotsar A, Pakarainen T, et al. Expression oF CAMP and creb in the human penis. J Men's Health. 2019;15(4):12-7. https://doi. org/10.22374/jomh.v15i4.145

31. Crowley LC, Marfell BJ, Scott AP, Waterhouse NJ. Quantitation of apoptosis and necrosis by annexin $\mathrm{V}$ binding, propidium iodide uptake, and flow cytometry. Cold Spring Harb Protoc. 2016;2016(11). https://doi.org/10.1101/pdb.prot087288 
32. Gallo-Oller G, Ordoñez R, Dotor J. A new background subtraction method for Western blot densitometry band quantification through image analysis software. J Immunol Methods. 2018;457:1-5. https://doi.org/10.1016/j.jim.2018.03.004

33. Pang X, Qiao J. Galectin-1 inhibits PDGF-BB-induced proliferation and migration of airway smooth muscle cells through the inactivation of PI3K/Akt signaling pathway. Biosci Rep. 2020;40(6): BSR20193899. https://doi.org/10.1042/ BSR20193899

34. Dong Q, Jie Y, Ma J, Li C, Xin T, Yang D. Renal tubular cell death and inflammation response are regulated by the MAPKERK-CREB signaling pathway under hypoxia-reoxygenation injury. J recept Signal transduct Res. 2019;39(5-6):383-91. https://doi.org/10.1080/10799893.2019.1698050

35. Li R, Xin T, Li D, Wang C, Zhu H, Zhou H. Therapeutic effect of Sirtuin 3 on ameliorating nonalcoholic fatty liver disease: The role of the ERK-CREB pathway and Bnip3-mediated mitophagy. Redox Biol. 2018;18:229-43. https://doi.org/10.1016/j.redox.2018.07.011

36. Koga Y, Tsurumaki H, Aoki-Saito H, Sato M, Yatomi M, Takehara $\mathrm{K}$, et al. Roles of cyclic AMP response element binding activation in the ERK1/2 and p38 MAPK signalling pathway in central nervous system, cardiovascular system, osteoclast differentiation and mucin and cytokine production. Int J Mol Sci. 2019;20(6):1346. https://doi.org/10.3390/ijms20061346 